Article

\title{
Development of ICT for Leaching Monitoring in Taiwan Agricultural LTER Stations
}

\author{
Yankuang Chan ${ }^{1}$, Jhenghong $\mathrm{Hu}^{1}{ }^{1}$, Chiaoying Chou ${ }^{1}$, Chongyi Liao ${ }^{2}$ and Chiling Chen ${ }^{1, *}$ \\ 1 Taiwan Agriculture Research Institute, Council of Agriculture, Executive Yuan, Taichung 41362, Taiwan; \\ lterwsn@tari.gov.tw (Y.C.); tutech@tari.gov.tw (J.H.); uav@tari.gov.tw (C.C.) \\ 2 Yanchao District Office, Kaoshiung City Government, Kaohsiung 82446, Taiwan; mvemjsunp@gmail.com \\ * Correspondence: chiling@tari.gov.tw; Tel.: +886-4-2331-7407
}

Received: 28 April 2017; Accepted: 27 June 2017; Published: 30 June 2017

\begin{abstract}
In order to study the groundwater subsidy from different cropping systems, leaching monitoring in Taiwan started in 2008 and implemented agricultural long-term ecological research (LTER) stations. Initially, leaching data was received by lysimeters, and then collected manually by laborers in the field twice per month. The cost of data collection and transmission is high, real-time monitoring is not possible, and maintenance of instruments is inefficient. In this study, the goal is to develop a data transmission path. ICT (Information and Communication Technology) with different data transmission schemes was applied to improve the efficiency and immediacy of data transfer from the field to the databases in labs. Between 2010 and 2017, four versions of ICT have been developed and applied in LTER stations. WiFi, 2.5G (General Packet Radio Service, GPRS), 3G/4G network transmission, and Arduino cores are applied in different ICT versions. The first version of data transmission used data loggers, developed by the original factory, with a lower cost of renovation of instruments. However, complicated transmission paths, diverse instruments, poor weather resistance, and lack of wireless functionality are the limitations of the first version. Those limitations had been overcome by the second and third versions by using 2.5G (GPRS) and 3G/4G network transmission, respectively. Nevertheless, these versions are limited to the processes of data compression and encryption transmission which were developed by the system vendors. In addition, data can only be collected through the webpage provided by the vendors, instead of being received directly from the database using SQL (Structured Query Language). This is inappropriate for advanced data treatment, organization, and analysis. Finally, the fourth version of data transmission has been developed using Arduino. This system allows redesigning of the data loggers and transmission instrument with more feasibility and flexibility. Radio Frequency (Radio frequency, RF) has been imported into the transmission path to receive data from diverse instruments with fewer data loggers. In conclusion, ICT technological advancement with its advantages of reasonable cost and high flexibility and feasibility, Arduino and other open source operation systems can be used to develop the data loggers and related instruments to meet the needs of users. Therefore, ICT is the most appropriate strategy to develop the long-term monitoring system in the field and to apply to other environment monitoring systems.
\end{abstract}

Keywords: lysimeter; data loggers; data transmission; Arduino; real-time monitoring; database; open source

\section{Introduction}

Information and Communication Technology (ICT) is technology for data collection and digitization through instruments and sensors that transfer data to storage devices. Digital information is transmitted through a variety of communication technologies, including wired and wireless, to the endpoint. The world is moving towards micro- and nano-scale devices, and wireless communication 
technologies are replacing their wired counterparts [1]. Wireless communications, such as WiFi, Bluetooth, and 4G communication, are currently the mainstream choices used to reduce the consumptions of long-term maintenance. In addition, endpoints such as data loggers, databases, and cloud storage are used to receive information from sensors and store it for a long time. Subsequently, long-term analysis and big data utilization can be carried out. ICT technologies such as automation, robots, telemedicine, and mobile devices, are being widely applied. The development of advanced internet and the convenience of interactivity between devices are key components of the internet of things (IOT). IOT is expected to offer advanced connectivity of devices, systems, and services that goes beyond machine-to-machine communications (M2M) and covers a variety of protocols, domains, and applications [2]. Our environment and surrounding objects are becoming communicative. New applications thus arise in domains such as logistic, health, rescue, environmental preservation, etc. [3].

Nowadays, within an ICT data transmission system, data can be exchanged between the equipment and facilities in a wireless regional network. Thus, a data logger can receive data from the equipment within the wireless regional network and then send it to the terminal storage database through a $4 \mathrm{G}$ network. There are many different schemes of ICT data transmission on the market. WiFi is the most popular wireless network transmission technology, with transmission speeds as fast as $54 \mathrm{Mbps}$; however, its transmission range is short-about $45 \mathrm{~m}$-and the power consumption is large, so it is only capable of serving as a home network [4]. Bluetooth wireless technology can be applied for exchanging data over short distances-about $10 \mathrm{~m}$-from fixed and mobile devices. It is reliable point-to-multipoint data transfer. However, it is not appropriate for use in a wireless network transmission system with a limited number of access nodes (maximum capacity is seven nodes at once) [5]. RF (radio frequency) communication is well-known for its low-power consumption with a battery support system for moderate-range transmission (as far as $2 \mathrm{~km}$ ). RF can be used to develop a wireless network transmission system with more than 1000 nodes without the complicated communication protocol and multiple facilities required by other technologies [6]. LoRa (Long-Range) is a low-power wide area network developed by IBM in 2015. It is specified for low-power consumption, long-range transmission (as far as $8 \mathrm{~km}$ ), and low-data-rate communications infrastructure that needs fewer base stations to serve more simple devices such as online smoke detectors, temperature sensors or smart electrical heating controllers [7]. In Table 1, the advantages, limitations, and applications of different schemes, i.e., WiFi, Bluetooth, RF, and LoRa, are listed.

Taiwan agricultural long-term ecological research (LTER) stations, built in 2006, were set up to investigate the effects of different managed and cultivated systems on biodiversity, productivity, and environment. Lysimeters were set up in 2008 and continually increased between 2008 and 2016. Initially, data transmission mainly relied on cable transmission, with sensors transmitting digital information via RS-232 or RS-485 directly to a computer by transmission line. This method required that the computer be located at the experimental site long-term, and connected to the sensor. However, the equipment cost was high, and maintenance was costly. Subsequently, the sensor manufacturer designed the data loggers, which replaced the computer. The number of data loggers decreased drastically, and not only was cost reduced but the system became more adapted to the climate. Nevertheless, research staff still have to bring a laptop and transmission line to the experimental site in order to download data from data loggers to a computer periodically.

Sensor communication and the internet are formed as a network system, which can transmit and analyze data, working as a sensor network. The data collection system is different from traditional systems. It provides brand new application, especially in ecological research and resource management monitoring [8]. Wireless sensor networks (WSN) are well suited for long-term environmental data acquisition and representation via IOT [9]. IOT is also used in detailed fields of environmental monitoring and management, including underwater resources management [10]. 
Table 1. Comparison of different transmission schemes.

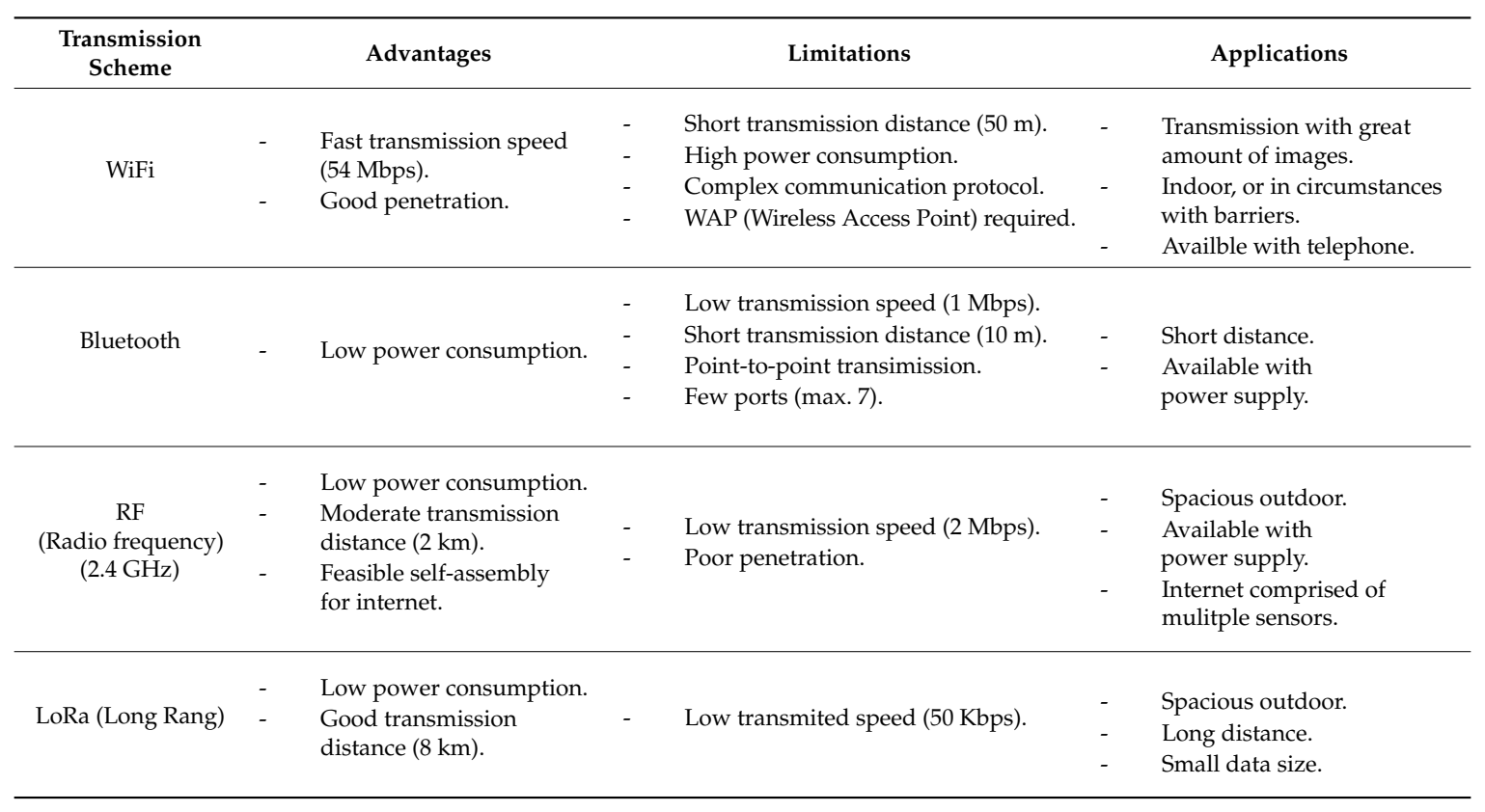

The strengths of the ICT system are real-time and remote monitoring, and it can lower the cost of labor. Also, maintenance personnel only need to check information delivered from remote devices for a period of time, and then the condition of equipment operation can be controlled. In advanced applications, wireless technology can facilitate field investigation by not only monitoring in real-time, but also observing under severe weather conditions, which had not been possible with traditional field works. For instance, United States Virginia Coast Reserves (VCR) includes three kinds of ecosystems: mainland, lagoons, and barrier islands. The long-term ecological research team, University of Virginia, investigates the local biosphere, climate, marine sphere, coastal environment, and soil hydrology. All this research takes advantage of wireless network technology to make the work more time-saving and labor-saving, and to make data collection more complete [11].

IOT and cloud computing technology are used to monitor the reservoir and establish an early warning system in mines [12]. Agricultural IOT equipment is often used in greenhouse monitoring. The collected information can be applied to agricultural research and facility management [7].

In this study, we aim to apply a variety of possible transmission technologies to collect leaching data from the lysimeters in fields and transmit it to the database directly and wirelessly. Ultimately, the aim of this research is to reach the goals of real-time monitoring, reduction of labor cost, and improvement of maintenance efficiency. Secondly, along with the improvement of devices, the advantages and disadvantages of diversity of transmission path are discussed, and the potential solutions to difficulties with ICT applications are assessed and suggested.

With the emergence of Arduino and Raspberry pi, the difficulty and cost of IOT development has decreased. Raspberry pi has the advantages of low cost and low power consumption, which makes it relatively easy to implement [13]. However, the operation system in Arduino is comparatively easier and is much more appropriately applied to sensor communication. In this study, Arduino is applied in the ICT system along with various communication methods, data storage modules, and sensors. Thus, research and development are expected to be more flexible and feasible, and it is more useful for field monitoring and data transmission devices. 


\section{Materials and Methods}

\subsection{Study Sites}

In order to apply this study in the field with the appropriate agricultural management with minimum input, subtropical agricultural long-term ecological research (LTER) stations were targeted. LTER stations were initially established in 2006, and were set to investigate the effects of different managements and cultivated systems on biodiversity, productivity, and environment. Five stations were targeted and their locations are shown in Figure 1.

1. Two field crop ecosystems: Yuin-Lin branch station (7.0 ha, Tainan District Agricultural Research, COA) and Chi-Ko branch farm (8.0 ha, CAEB, TARI) with lowland and lowland-upland rotation.

2. Two orchard ecosystem: Chia-Yi Branch Litchi Orchard (2.5 ha, CAEB, TARI) and Gukeng Branch Farm Litchi Orchard (2.5 ha, CAEB, TARI).

3. One tea garden ecosystem: Ming-Jian tea garden (1.32 ha) located at Tea Research and Extension Station, Ming-Jian village, Nantou County.

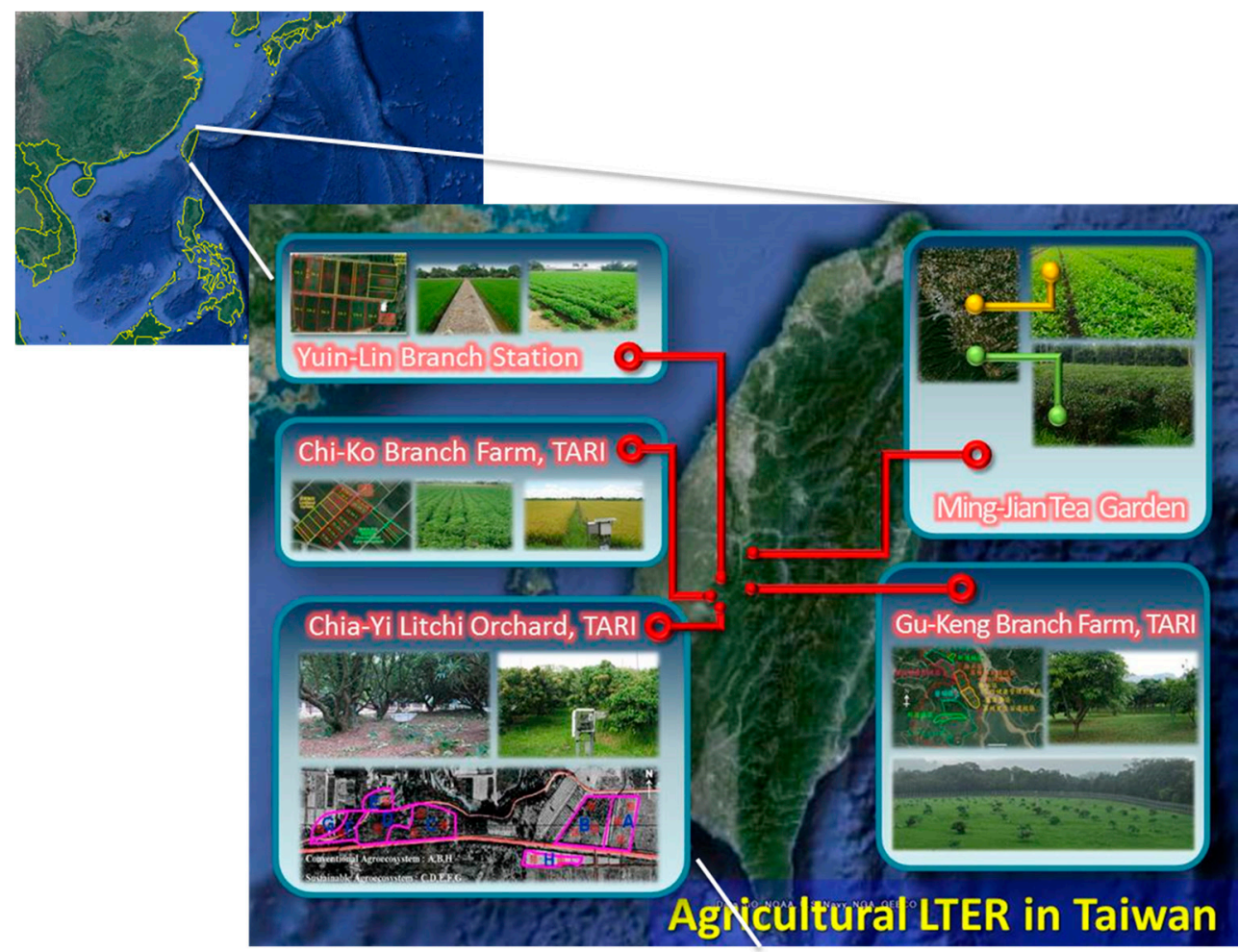

Figure 1. Locations of four agricultural long-term ecological research (LTER) stations in central Taiwan.

In these LTER stations, treatments of managed systems include both conventional agro-ecosystem management (CA) with high chemical input and sustainable agro-ecosystem management (SA) with low chemical input in different rotation systems. Data on field tractability, soil fertility, nitrogen leaching, production cost, disease severity in crops, pest and insect indications, dynamic of weeds, biodiversity index, and greenhouse gas emissions was collected at LTER stations as well.

\subsection{Measurement by Using Lysimeters}

Lysimeters are used in the measurement of leaching in this study. Lysimeters are commonly used in water flow and solute transport studies in soils. They are known to be of major importance in controlling and measuring water components, chemical concentration and fluxes in soil. Recently, 
two types of lysimeters, G2 and G3, were applied in Taiwanese agricultural LTER stations (Figure 2). Lysimeters G2 and G3 are low-cost drain gauges for measuring deep drainage rates in unsaturated soils, in addition to collecting soil water samples for chemical analysis to help assess potential groundwater contamination, monitoring groundwater leaching, and measuring deep percolation accurately.

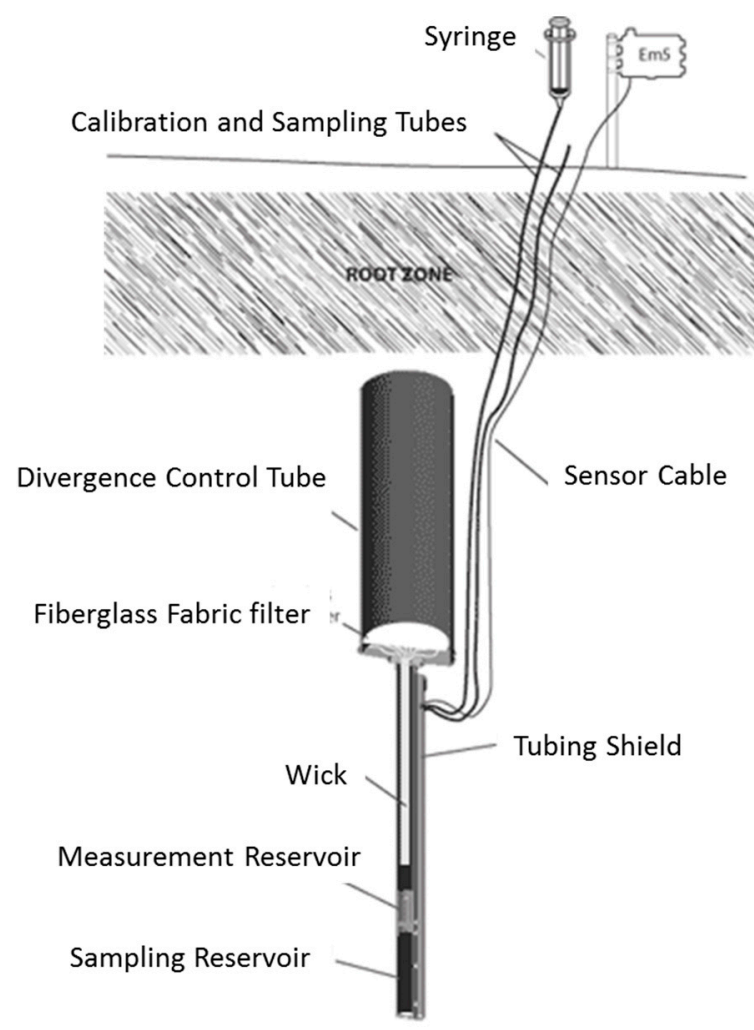

(a)

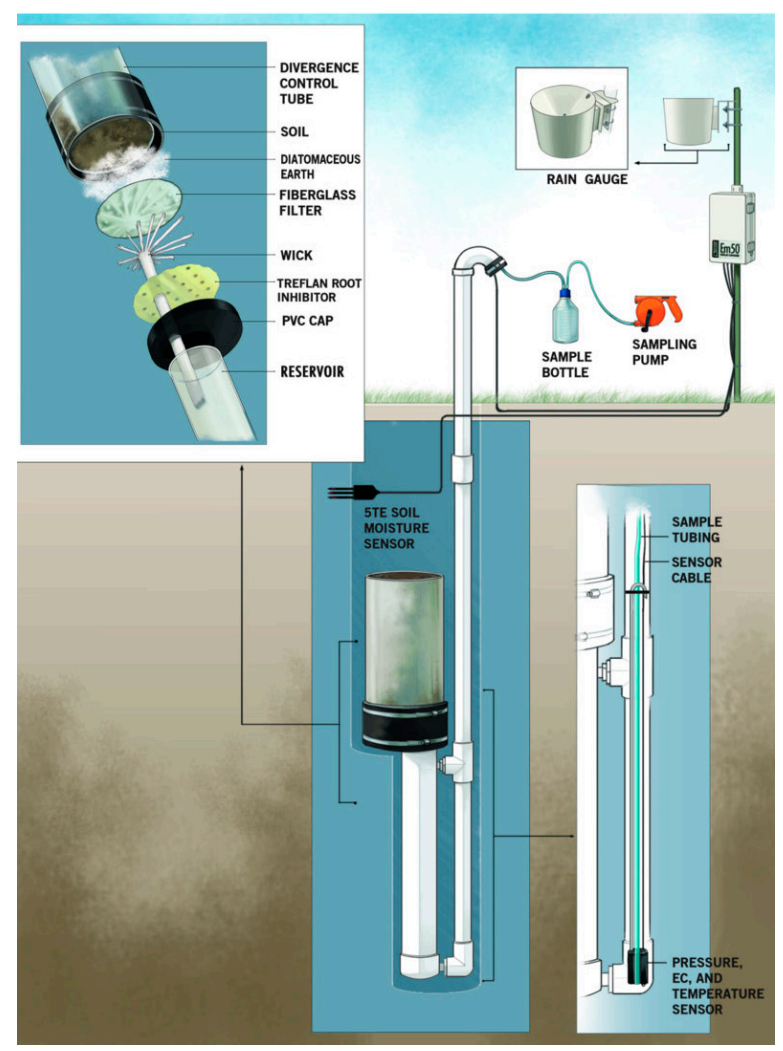

(b)

Figure 2. Construction and measurement illustration of G2 (a) and G3 (b) lysimeters (Reproduced with permission from Decagon Devices, Inc., Drain Gauge Models G2 and G3, Operator's Manuals; published by Decagon Devices, Inc., 2014) [14].

G2 lysimeters measure the water level and drainage frequencies in the measurement reservoir, and then estimate the amount of leakage. G3 lysimeters directly measure the water level from the communication pipe, and then estimate the amount of leakage. G2 lysimeters take samples with syringe negative pressure; while G3 lysimeters take samples directly with drainage pumpers. However, G2 lysimeters are limited by errors caused in drainage measurements when flooding measurement chambers with high water tables.

New G3 lysimeters have a completely sealed system to protect from high water tables. In advanced systems, this new drain gauge can work in both saturated and unsaturated conditions without digging up the entire drain gauge to replace the sensor, with larger sampling reservoirs, and can be integrated with EC sensors to allow monitoring when solute fluxes occur. Recently, G3 lysimeters have been gradually applied to all of the LTER stations for monitoring groundwater leaching, measuring irrigation drainage, and improving the accuracy of data and durability of facilities.

\subsection{Development of Data Transmission Path}

In the development of ICT data transmission facilities in agricultural LTER stations, leaching data is monitored by sensors (i.e., lysimeters), collected by data loggers, and then transferred to a database in labs with the internet (Figure 3). In the field, there are two major schemes to transfer data 
received by lysimeters to data loggers for storage, namely wired transmission and RF (Radio Frequency, 2.4 GHz) wireless transmission. Using wired transmission, data can be stored directly by the SDI-12 communication protocol interface of the data loggers; while using RF (2.4 GHz) wireless transmission, lysimeters are connected to the RF $(2.4 \mathrm{GHz})$ wireless transmission controller, and data will be stored wirelessly by the data loggers inside of the RF $(2.4 \mathrm{GHz})$ wireless transmission receiver. When data is received by the data logger and stored within a memory card or WiFi memory card, data will be periodically transferred to the terminal computer database for further storage and management. Data transmission is applied either by WiFi hotspot internet connections or by mobile internet connections (i.e., 2.5G (General Packet Radio Service, GPRS), 3G, 4G, etc.). In one method, data stored within the database can be downloaded through an application program or webpage for advanced analysis and research; alternatively, using the other method, data stored within the database can be displayed as charts or tables on the webpage directly, in order to monitor the condition of instruments and the trends in data.

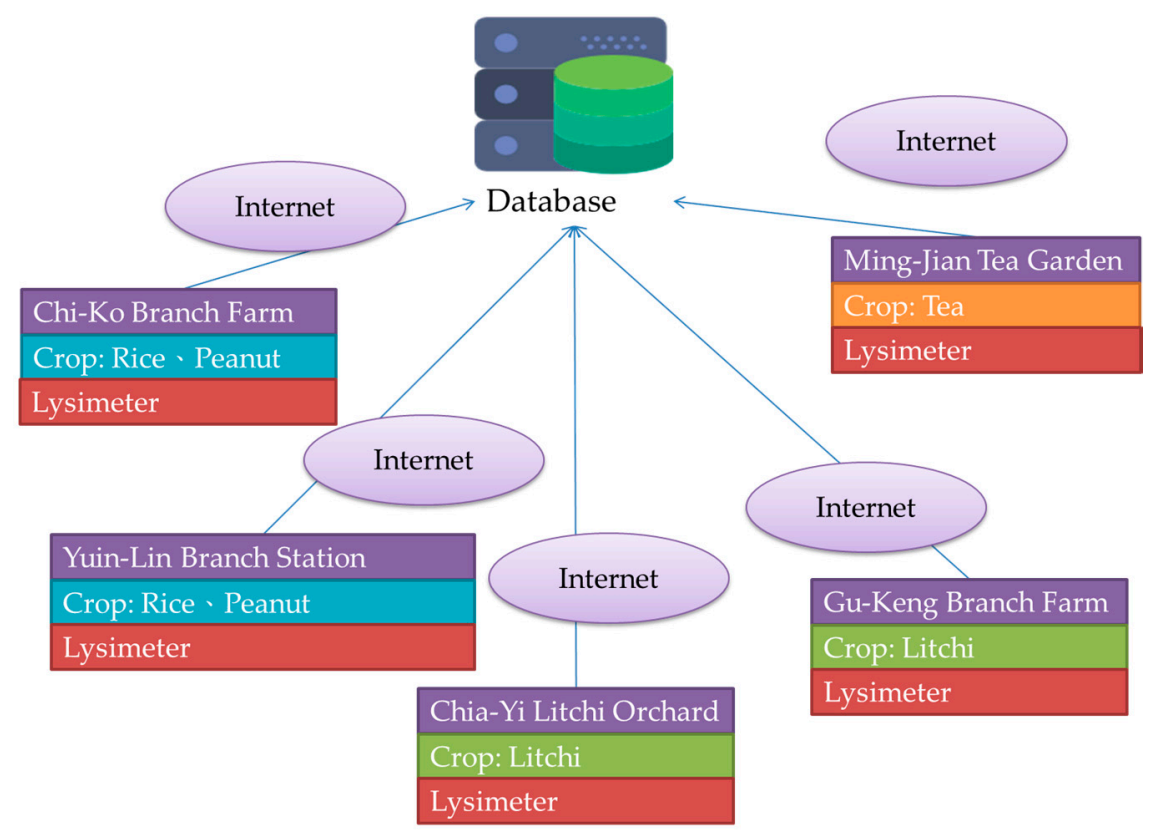

Figure 3. The framework of data transmission between lysimeters in the field and the database in labs. The path of data transmission has replaced laborers with internet.

\subsection{Data Qualiy and Data Quantity Analysis}

The leaching data collected by G2 and G3 lysimeters assembled with different versions of ICT systems are examined with the precipitation records, in order to test if the leaching data collected by lysimeters can respond to the variation of precipitation records accurately. In the crop LTER stations, the precipitation record is collected according to the irrigation schedule in each crop season. For the orchard and tea garden LTER stations, precipitation data is collected from local agricultural weather stations nearby. For instance, in Ming-Jian tea garden LTER station, the daily precipitation record is calculated as the average of three days, including the day, the day before, and two days ago. This is because the daily leaching is influenced by the rainfall of the day itself and the previous two days. In this study, simple linear regression is applied to examine the patterns between data collected by lysimeters and from the precipitation record [15].

\section{Results}

The processes of ICT data transmission in different versions and the relative challenges and solutions between different versions were described as the following: 


\subsection{First Version of ICT Data Transmission}

In 2010, the first version of ICT data transmission had been developed for leaching monitoring in Taiwanese agriculture LTER stations, including Yuin-Lin branch station, Chi-Ko branch farm, and Chia-Yi Branch Litchi Orchard. However, in Ming-Jian tea garden, data was still collected and transferred manually. The lysimeters in the field were connected to the Internet for real-time monitoring (Figure 4). The purpose of this first version of ICT data transmission is to store data by using existing instruments with light and handy parts from the general vendors. In the past, 2.5G, (GPRS) and 3G wireless networks were not popular. The ability to provide wired internet and WiFi is the major limitation in this environment.

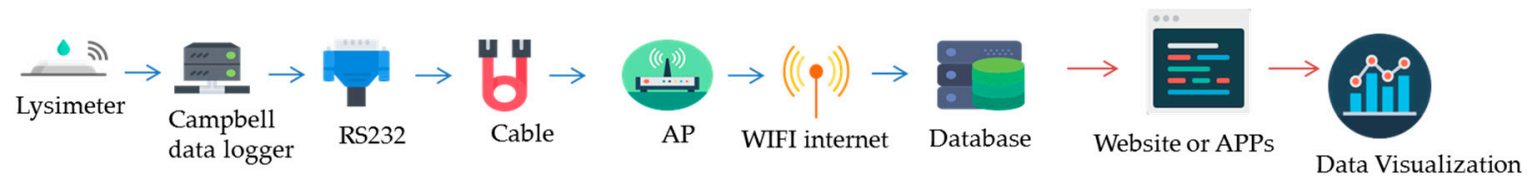

Figure 4. Path of the first version of Information and Communication Technology (ICT) data transmission.

In order to transfer the data from lysimeters and existing data loggers in the field to the database in labs with minimum cost, the data transmission path is relatively complicated (Figure 4). Firstly, the old exchange interface of the data logger, RS-232, needs to be exchanged to an Ethernet packet. Secondly, Wi-Fi compatible devices connect to the Internet via a wireless access point (WAP), and then transfer data to the database through the Internet.

Multiple hardware devices were connected to each other with cables in the first version of ICT data transmission. It is a challenge to maintain those devices and cables inside the cabinet with small size. The space of the cabinet is compressed to those devices as well. Therefore, the operation of the first version of ICT data transmission declined quickly. In addition, it is difficult to cover the whole region in the spacious fields with a WiFi signal, and the internet connection by WiFi was interrupted frequently.

\subsection{Second Version of ICT Data Transmission}

Because of the popularity and reasonable cost of $2.5 \mathrm{G}$ (GPRS) network transmission equipment, the second version of ICT data transmission had been developed by the cooperation of domestic vendors. The new version facility had been applied in five of the LTER stations. In particular, in Chia-Yi Branch Litchi Orchard, the WiFi signal is unstable because of the dense coverage of fruit tree crown. Crown coverage is not a challenge in Gukeng Branch Farm Litchi Orchard, which is isolated and has no WiFi provided from national telecommunication services.

Therefore, the second version of ICT data transmission improved on the limitations of the first version. Data loggers, developed by a domestic vendor, integrate the multiple data transmission facilities. The processes of data exchange were simplified and data received in the field could be transferred directly to the database in labs by using GPRS (Figure 5).

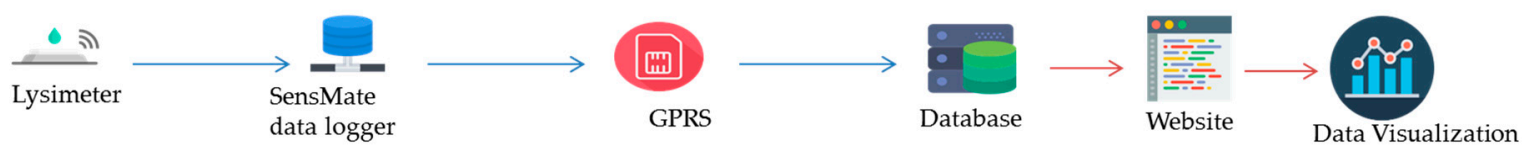

Figure 5. Path of the second version of ICT data transmission.

\subsection{Third Version of ICT Data Transmission}

With the development of 3G/4G networks and the strategies of removing the 2.5G (GPRS) base stations by the government, the $2.5 \mathrm{G}$ (GPRS) signal is gradually becoming weakened and unstable. 
The third version of ICT data transmission was developed to overcome the weakness and interruption of the 2.5G (GPRS) signal. New data loggers provided by domestic vendors can transfer data by using 3G/4G networks (Figure 6).

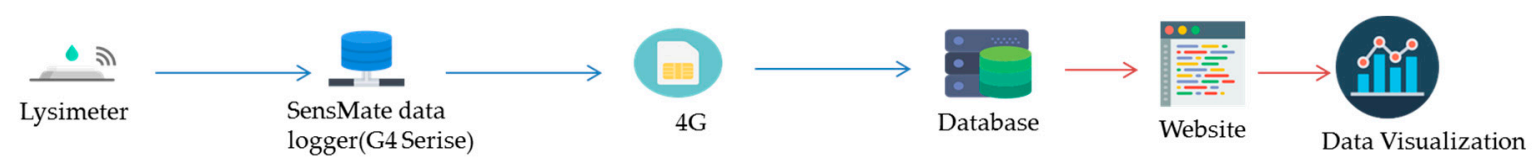

Figure 6. Path of the third version of ICT data transmission.

In 2015, the third version ICT was firstly applied in Ming-Jian tea garden. The new data transmission path is moderately adjusted from the old version (Figure 6). The old data loggers which are adapted by GPRS were replaced by data loggers which can be adapted by $3 \mathrm{G} / 4 \mathrm{G}$. In this case, the instability and weakness of data transmission could be solved, completely. Further, the new ICT facility can be operated even through the termination of $2 \mathrm{G}$ in the near future.

Compared with the first version, the data transmission paths in the second and third versions are relatively concise and the number of ICT facilities are reduced. However, data stored inside of the data logger had been compressed and encrypted, meaning that data transmitted to the database cannot be used and extracted by SQL directly. Therefore, data needs to be downloaded from a webpage provided by vendors for the advanced charts reporting and statistical analysis. The core instrument and key technology of ICT data transmission are mastered by the vendors. Users cannot deal with the malfunction in real time, and cannot replace or modify the facilities by themselves.

\subsection{Fourth Version of ICT Arduino Core}

Arduino is an open source microcontroller kit for building digital devices and interactive objects that can sense and control objects in the physical world. The space and allocation of Arduino cores is relatively small and simple. In addition, Arduino boards are available commercially in preassembled form, or as do-it-yourself kits. Therefore, development of self-designed data loggers and controllers turned out to be comparatively feasible. Self-designed data loggers integrated with RF $(2.4 \mathrm{GHz})$ can develop a wireless network transmission system for leaching monitoring by using lysimeters in a whole LTER station (Figure 7). More than 1000 network nodes come with a data logger and Arduino core device which is capable of receiving all of the data from lysimeters in one LTER station.

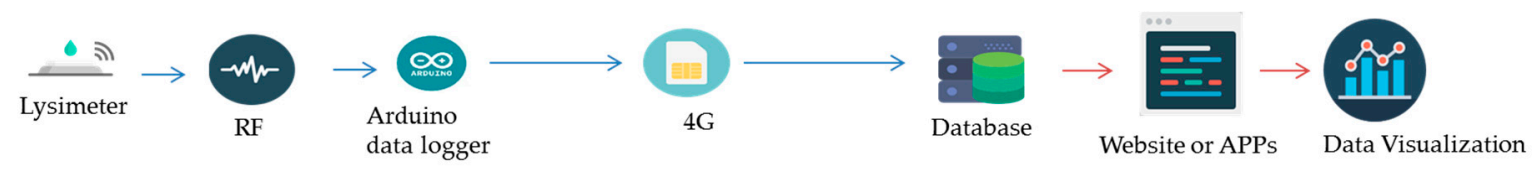

Figure 7. Data transmission path of ICT Arduino core fourth version.

According to the concept of the Internet Of Things (IOT), a data logger with a $4 \mathrm{G}$ network is applied to transmit data from Arduino in the field directly to the database in labs (Figure 7). This new version has greatly improved the convenience of wireless transmission and reduced the cost of ICT facilities [15]. The process of data management and operation of ICT facilities can be completely manipulated by users [16]. The broken ICT facilities of the first version and second version were replaced by Arduino cores. In addition, fourteen Arduino cores were applied to the Chi-Ko branch farm.

\subsection{Quality and Quantity of Data Received from ICT for Leaching Monitoring}

Leaching data collected by lysimeters and the precipitation records collected by local agricultural weather stations in 2014 in the Ming-Jian tea garden LTER station are illustrated in Figure 8. The pattern 
of leaching data reflects the pattern of precipitation records. It implies that data collected by lysimeters and the ICT data transmission system work well and properly. For instance, in Figure 8, the peaks of precipitation during a heavy rain season in May and during typhoon season between July and September are reflected by the leaching peaks. On the other hand, during the dry season in January to April and in October to December, there are off-peaks in both leaching and precipitation. Therefore, when the amount of precipitation is heavier, the amount of the leaching is raised accordingly. In addition, the results of simple linear regression show that the relation between leaching (average in 3 days) and precipitations (average in 3 days) is significantly positive $\left(p<0.001, \mathrm{r}^{2}=0.28\right)$. However, the leaching is influenced by other factors, i.e., physical properties of soil, vegetation species, growth situation, weeding management, etc. According to the results, leaching data collected by the lysimeters and ICT data transmission system is one of the most appropriate monitoring strategies. Consequently, the quality of data is examined and the result reveals that the leaching data reflects the precipitation records positively.

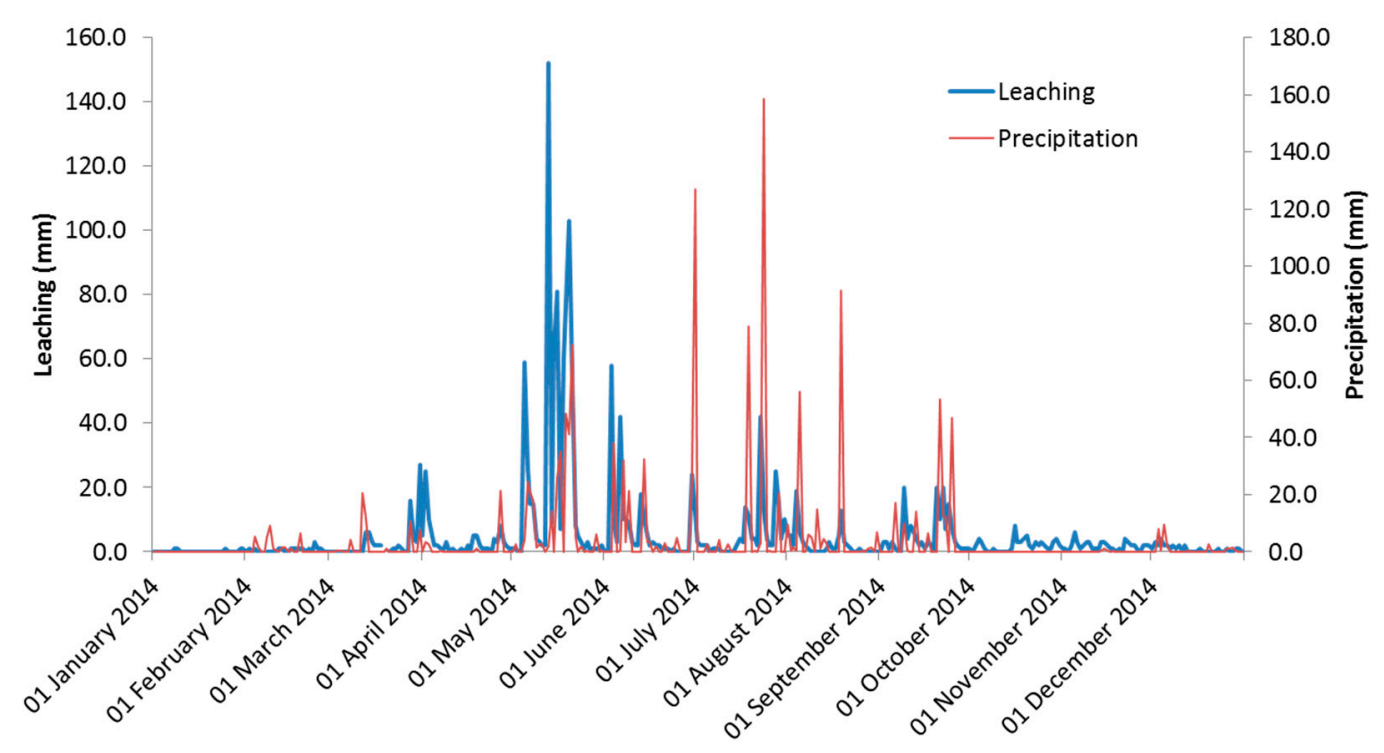

Figure 8. The daily patterns of leaching and precipitation in 2014.

In addition, data quantity is examined by frequency of data received from the data logger and ICT data transmission systems. Here, the data loggers developed at the original factory, by vendors in Taiwan, or by Arduino, can set up the frequency of data receipt. In this study, the frequency of leaching data receipt is every three hours. In total, there are 2920 records received by each lysimeter every year. For the advanced data analysis, each of the leaching data will be accumulated daily as one record. In general, all of the data is accurately received and the quantity of data is enough for the advanced statistical analysis.

\section{Discussion}

The ICT facilities for leaching monitoring have been improved from first versions to fourth versions between 2010 to the present. As a result, Arduino cores have been adopted to develop the data transmission path with high flexibility and feasibility. The comparison among different versions of ICT facilities is organized in Table 2. In subsequent versions, the extensibility has been improved, the complexity of maintenance has been moderated, and the cost has decreased. The original purpose of ICT was to minimize the cost with real-time monitoring. With the progress of ICT technology, data transmission can be developed with open source operation systems to achieve different requirements for specified circumstances. 
Table 2. Comparison among different versions of ICT facilities.

\begin{tabular}{ccccc}
\hline Versions & 1st & 2nd & 3rd & 4th \\
\hline Data logger & $\begin{array}{c}\text { Original factory } \\
\text { production }\end{array}$ & $\begin{array}{c}\text { Domestic vendor } \\
\text { development }\end{array}$ & $\begin{array}{c}\text { Domestic vendor } \\
\text { development }\end{array}$ & Arduino core \\
\hline $\begin{array}{c}\text { Network } \\
\text { transmission mode }\end{array}$ & $\mathrm{WiFi}$ & $2.5 \mathrm{G}(\mathrm{GPRS})$ & 3G/4G & 4G \\
\hline Extensibility & $\mathrm{Bad}$ & Moderate & Moderate & Good \\
\hline $\begin{array}{c}\text { Power } \\
\text { Consumption }\end{array}$ & High & Moderate & Moderate & Low \\
\hline Cost & 1000 USD/Sensor & 830 USD/Sensor & 900 USD/Sensor & $\begin{array}{c}150-250 \\
\text { USD/Sensor }\end{array}$ \\
\hline
\end{tabular}

According to the ICT development of the four versions, potential solutions to the challenges in the field are provided as following.

\subsection{Power Supply}

The first challenge when developing ICT facilities in the field is power supply. Power supply is required for ICT facilities, monitoring sensors, and diverse instruments. Power supply is the essential equipment when establishing LTER stations. However, power supply is unstable and insufficient because of wire cable being destroyed by a lightning strike, wild animals and human beings.

One of the potential solutions to this is solar panels compatible with charge controllers and rechargeable batteries. The most efficient source of environmental energy is solar power [17], providing most of the energy with very high efficiency [19]. Use of solar energy could be helpful in energy supplies to batteries of the sensor nodes [20]. However, power is highly demanded by G2 lysimeters and the WiFi network transmission system of first version ICT. In addition, G2 GPRS of second version ICT and data loggers with G3/G4 of the third version demanded more power supply than earlier versions. Therefore, after a few cloudy and/or rainy days, power supply by solar panels will be extremely limited.

Data loggers of the fourth version not only save power with the new version sensor of ICT Arduino core, but the infrastructure program of the fourth version is also modified to advance power saving by setting up sleep, wake-up, and data transmitting modes. Therefore, power supply by solar panels has turned out to be a possible solution, and difficulties of developing an ICT data transmission network are reduced.

\subsection{Transmission Instruments: Failure Rate and Maintenance}

In the field, instruments are influenced by the weather, wild animals, farming practices, etc. For the first version ICT, the space of the cabinet housing is small with pores, so the equipment inside of the cabinet is easily destroyed by biting, spawning, nesting, etc. In addition, the cables inside of the cabinet are crisscrossed and disadvantageous for maintenance purposes.

This challenge had been overcome by the second and third ICT versions. The space of the new cabinet is enlarged, closed, and resistant to destruction by wild animals and the weather. However, ventilators with a gauze design in the new cabinets may allow small-size insects to nest, so the cables and equipment inside the cabinets can still be damaged.

In order to overcome the challenge of the second and third ICT versions, the fourth version ICT Arduino core designed a new small case which is waterproof sealed. The connections between power supplies, the interface of the sensor and antenna, and data loggers are completely sealed by silicon and/or rubber gaskets. Therefore, ICT facilities inside new cases are entirely separated from water and wild animals. 


\subsection{Data Warehouse and Database Management}

The development of ICT second and third versions was in cooperation with system vendors, and data stored inside the data loggers developed by vendors was compressed and encrypted. Therefore, data stored in the database cannot be used and extracted by SQL (Structured Query Language) directly. The leaching data collected by lysimeters in LTER stations is not required to be compressed or encrypted, because of the moderation of monitoring frequencies and data size.

Therefore, data needs to be stored as an exchangeable format to allow further reading and writing in the database using SQL. In addition, the database should be developed with the functions of data extraction, data analysis, chart display, etc. A webpage which comes with the database is needed to increase the interactions between the database, applications, and users.

\subsection{Cost Control}

ICT facilities can reduce the cost of data transmission. The overall profit of ICT facility establishment should be considered for cost control. The cost of first version ICT is about US\$1000 and it is reasonable, because the data transmission system is developed using the existing data loggers and WiFi network, and new equipment is inexpensive. However, if new data loggers and a WiFi network could be developed by users, the cost of development would be lower.

The costs of the second and third ICT versions are about $\$ 830$ and $\$ 900$, respectively. Their costs are higher than the first version. Although the cost of data loggers developed by the domestic vendors is similar to those developed by original factories, the expenditure of the peripheral equipment remains high. The cost of $2 \mathrm{G}$ (GPRS) and $3 \mathrm{G} / 4 \mathrm{G}$ networks is inexpensive because transmission traffic is moderate.

The cost of Arduino fourth version ICT is about $\$ 150-250$, which is relatively reasonable because of the low price of assembling parts and self-designed system. The 4G transmission system costs about $\$ 100$. In addition, the new cabinet is smaller and sealed, which can be compatible with solar panels, rechargeable batteries, etc. Therefore, the cost of ICT facilities has been greatly reduced but the efficiency and durability have been greatly improved.

Arduino cores come with high flexibility and feasibility to be able to connect with diverse sensors, and lysimeters are one of this kind of sensors. According to the data acceptability in both analog and digital data format, the ICT data transmission can be connected to different kinds of sensors such as weather station, soil hygrometer, soil conductance meters, greenhouse gas monitoring equipment, etc., for the potential advanced application in agricultural LTER stations in the future. The proliferation of devices with communicating-actuating capabilities is bringing closer the vision of an Internet of Things, where the sensing and actuation functions seamlessly blend into the background and new capabilities are made possible through access of rich new information sources. The evolution of the next version mobile system will depend on the creativity of users in designing new applications [21].

In this study, the usage of ICT data transmission is mainly designed for leaching monitoring for selected agricultural LTER stations. So far, it is under the test phase and only applied by us. In the future, whenever the system works as stably and efficiently as we expected, it will be promoted to others to meet their needs. According to our experiences, the ICT data transmission is feasible for a limited space cabinet because of its small size, compactness, and ease of handling. In addition, it is a low-power system, it can be powered by solar energy generation and the configuration of power lines can be simplified. Therefore, the system operates well in general, the wireless transmission is speedy, and it is weather durable - it is able to withstand the hot, humid, and windy conditions in Taiwan's farmlands.

\section{Conclusions}

Nowadays, ICT is properly developing. ICT facilities are applied to agricultural long-term monitoring and measurement with the advantages of low-cost, instant and remote monitoring. 
According to the popularity of open source technology, users can develop the data transmission system by using monitoring equipment, transmission paths, and power saving supplies by themselves, to meet the needs of different conditions in the field. In addition, data transmission systems come with long-range transmission technologies (i.e., RF and LoRa) which can develop more complete and compact data transmission structures. Therefore, users will be able to monitor long-term data more completely and more precisely with reasonable cost. In advanced applications, basic knowledge of programming and electrical hardware development is required by cooperating with other experts to achieve the specification and profession of experimental objectives. Ultimately, with the feasibility, flexibility, and extensibility of ICT facilities, users can develop data transmission with diverse schemes to satisfy their needs.

Acknowledgments: This study has been implemented since 2010 and has been funded by Ministry of Science and Technology, Taiwan (Grant No. NSC-100-2621-M-055-001 and NSC-101-2621-M-055-001) between 2011 and 2012 and by Council of Agriculture, Taiwan (Grant No. 102AS-7.1.2-CI-C1, 103AS-7.1.1-CI-C1, 104AS-7.1.1-CI-C2, and 105AS-7.1.1-CI-C1) between 2013 and 2016. In addition, the authors would like to thank The Taiwan Long-Term Ecological Research Network (TERN) for assistance on the field work, data collection, and technical support.

Author Contributions: Chiling Chen developed the scope of this study, planed the system, and advised and improved the processes and progress of this study. Yankuang Chan, Jhenghong $\mathrm{Hu}$, and Chongyi Liao designed the framework of data transformation, installed the systems, collected data, and take in charge of instruments management, maintenance, and improvement. Yankuang Chan, Jhenghong Hu and Chiaoying Chou wrote the first manuscript draft. Chiling Chen and Chiaoying Chou revised the manuscript draft. All authors have read and approved the final manuscript.

Conflicts of Interest: The authors declare no conflict of interest.

\section{References}

1. Raghavan, V.; Shahnasser, H. Embedded Wireless Sensor Network for Environment Monitoring. J. Adv. Comput. Netw. 2015, 3, 13-17. [CrossRef]

2. Fan, Y.; Yin, Y.; Xu, L.; Zeng, Y.; Wu, F. IOT based smart rehabilitation system. IEEE Trans. Ind. Inf. 2014, 10, 1568-1577. [CrossRef]

3. Mitton, N.; Simplot-Ryl, D. From the internet of things to the internet of the physical world. C. R. Phys. 2011, 12, 669-674. [CrossRef]

4. IEEE 802.11g-2003 Standard-Wireless LAN. Available online: https://standards.ieee.org/findstds/standard/ 802.11g-2003.html (accessed on 13 June 2017).

5. IEEE 802.15.1-2005 Standard. Available online: https:/ / standards.ieee.org/findstds/standard/802.15.1-2005. html (accessed on 13 June 2017).

6. Nordic Semiconductor: nRF24L01 Product Specification. Available online: http:/ /www.nordicsemi.com/ eng/nordic/download_resource/8041/1/95599466/2730 (accessed on 13 June 2017).

7. Zhao, J.; Zhang, J.; Feng, Y.; Guo, J. The study and application of the IOT technology in agriculture. Comput. Sci. Inf. Technol. 2010, 3, 462-465.

8. Lin, C.; Lu, S. Framework and ecological applications of sensor network. For. Res. Newsl. 2005, 12, 10-13.

9. Lazarescu, M.T. Design of a WSN platform for long-term environmental monitoring for IoT applications. IEEE J. Emerg. Sel. Top. Circuits Syst. 2013, 3, 45-54. [CrossRef]

10. Domingo, M.C. An overview of the Internet of underwater things. J. Netw. Comput. Appl. 2012, 35, 1879-1890. [CrossRef]

11. Chen, C. Wireless network program in uninhabited island-The network technology in coastal reserve, Virginia, U.S. For. Res. Newsl. 2006, 13, 10-13.

12. Sun, E.; Zhang, X.; Li, Z. The internet of things (IOT) and cloud computing (CC) based tailings dam monitoring and pre-alarm system in mines. Saf. Sci. 2012, 50, 811-815. [CrossRef]

13. More, R.P.; Hiwale, A.S. A Reconfigurable Smart Sensor Interface for Industrial WSN in IoT Environment. Int. J. Innov. Res. Sci. Eng. Technol. 2016, 5, 8986-8994.

14. Decagon Devices Inc. Drain Gauge Models G2 and G3, Operator's Manuals. Available online: http://www. decagondevices.eu/products/hydrology/lysimeters/ (accessed on 30 June 2017). 
15. Kenney, J.F.; Keeping, E.S. Linear Regression and Correlation on the chapter 15. In Mathematics of Statistics, Part 1, 3rd ed.; Kenney, J.F., Keeping, E.S., Eds.; Van Nostrand: Princeton, NJ, USA, 1962; pp. 252-285.

16. Seneviratne, P. Internet of Things with Arduino Blueprints: Develop Integrative Arduino-Based Internet Projects with Ethernet and Wi-Fi; Packt Publishing: Birmingham, UK, 2015.

17. Karvinen, K.; Karvinen, T.; Valtokari, V. Make Sensors: A Hands-On Primer for Monitoring the Real World with Arduino and Raspberry Pi; Maker Media Inc.: Sebastopol, CA, USA, 2014; p. 377.

18. King, R.; Law, D.; Edmondson, K.; Fetzer, C.; Kinsey, G.; Yoon, H.; Sherif, R.; Karam, N. 40\% efficient metamorphic gainp/gainas/ge multijunction solar cells. Appl. Phys. Lett. 2007, 90, 183516. [CrossRef]

19. Khan, J.A.; Qureshi, H.K.; Iqbal, A. Energy management in Wireless Sensor Networks: A survey. Comput. Electr. Eng. 2015, 41, 159-176. [CrossRef]

20. Roseline, R.A.; Sumathi, P. Solar power for Wireless Sensor Networks in Environment Monitoring Applications-A Review. Int. J. Sci. Res. Publ. 2014, 4, 1-3.

21. Gubbi, J.; Buyya, R.; Marusic, S.; Palaniswami, M. Internet of things (IoT): A vision, architectural elements, and future directions. Future Version Comput. Syst. 2013, 29, 1645-1660. [CrossRef]

(C) 2017 by the authors. Licensee MDPI, Basel, Switzerland. This article is an open access article distributed under the terms and conditions of the Creative Commons Attribution (CC BY) license (http://creativecommons.org/licenses/by/4.0/). 